\section{S105 DOES VITAMIN D DEFICIENCY INCREASE RISK OF ACUTE LUNG INJURY POST OESOPHAGECTOMY?}

doi:10.1136/thx.2010.150946.6

${ }^{1} \mathrm{R}$ C A Dancer, ${ }^{1} \mathrm{D}$ Park, ${ }^{1} \mathrm{~V}$ D'Souza, ${ }^{2} \mathrm{~F}$ Gao Smith, ${ }^{2} \mathrm{G} \mathrm{D}$ Perkins, ${ }^{1} \mathrm{D}$ R Thickett. ${ }^{1}$ University of Birmingham, Birmingham, UK; ${ }^{2}$ University of Warwick, Warwick, UK

Introduction Vitamin D has profound effects on the immune system and its deficiency has been implicated in increased risk of diseases such as tuberculosis and pneumonia. We have shown vitamin D levels to be lower in patients with Acute Lung Injury than in healthy or at risk controls. We hypothesised that vitamin D deficiency may be a risk factor for developing Acute Lung Injury (ALI) following transthoracic oesophagectomy.

Methods 25-OH vitamin $\mathrm{D}$ (tandem mass spectrometry) and 1.25$\mathrm{OH}$ vitamin $\mathrm{D}$ (ELISA) were measured in plasma samples taken from patients prior to oesophagectomy. IL-6, RAGE and HMGB-1 were measured by ELISA. Extravascular Lung Water (EVLW) measurements were recorded using a PiCCO catheter.

Results All patients undergoing oesophagectomy had insufficient levels of $25-\mathrm{OH}$ vitamin $\mathrm{D}$ ( $<75 \mathrm{nmol} / \mathrm{l}$, median $25.5 \mathrm{nmol} / \mathrm{l})$. 1.25 $\mathrm{OH}$ vitamin $\mathrm{D}$ levels ranged from 26 to $182 \mathrm{pmol} / \mathrm{l}$ (reference range 43-144 pmol/l). Patients who developed ALI more than $72 \mathrm{~h}$ postop had lower levels of 25-Vitamin D $(p=0.032)$. Very low levels of $25-\mathrm{OH}$ vitamin $\mathrm{D}(<15 \mathrm{nmol} / \mathrm{l})$ were significantly associated with elevated post-operative systemic inflammatory response (as demonstrated by higher plasma levels of IL- $6(p=0.006)$ and HMGB$1(p=0.04))$ with evidence of increased epithelial damage (elevated RAGE $(p=0.03))$. Levels of 25 vitamin $D_{3}<15 \mathrm{nmol} / 1$ were associated with greater post-operative increases in extra vascular lung water $(p=0.03)$. Patients with severe vitamin $d$ deficiency $(<20 \mathrm{nmol} / \mathrm{l})$ had a $40 \%$ risk of developing post-operative ALI compared to $15 \%$ in those with less severe deficiency $(p=0.03)$.

Discussion These results suggest that very low 25 vitamin $D$ levels in oesophagectomy patients are associated with an elevated postoperative systemic inflammatory response, increased alveolar epithelial dysfunction and an increased risk of developing lung injury. These data support the rationale for clinical trials of vitamin $\mathrm{D}$ replacement as a preventative therapy for acute lung injury.

\section{S106 POLYMORPHISMS IN GENES ENCODING RAGE OR RAGE LIGANDS PREDISPOSE PATIENTS TO ADVERSE OUTCOMES FOLLOWING SURGERY NECESSITATING CARDIOPULMONARY BYPASS}

doi:10.1136/thx.2010.150946.7

${ }^{1} \mathrm{~N}$ Zakeri, ${ }^{1} \mathrm{~B}$ Creagh-Brown, ${ }^{1} \mathrm{~L}$ R Hector, ${ }^{1} \mathrm{R}$ J Hewitt, ${ }^{1} \mathrm{~A}$ L Lagan, ${ }^{1} \mathrm{G} J$ Quinlan, ${ }^{2} \mathrm{P}$ Pantelidis. ${ }^{1}$ Department of Critical Care Medicine, National Heart and Lung Institute, Royal Brompton Hospital NHS Foundation Trust, Imperial College, London, UK; ${ }^{2}$ Interstitial Lung Disease Unit, National Heart and Lung Institute, Royal Brompton Hospital NHS Foundation Trust, Imperial College, London, UK

Background Surgery necessitating cardiopulmonary bypass (snCPB) induces a systemic inflammatory response which can lead to organ dysfunction, including acute lung injury (ALI). Polymorphisms in inflammatory genes have been linked to adverse clinical outcomes following snCPB. The receptor for advanced glycation end products (RAGE) is an inflammation-perpetuating pattern recognition receptor. We investigated the hypothesis that polymorphisms in genes encoding RAGE or RAGE ligands predispose patients to a more severe systemic inflammatory response and the development of ALI after snCPB.

Methods In a nested unmatched case-control study 187 UK Caucasian patients undergoing cardiac surgery necessitating CPB were genotyped for eight biallelic single nucleotide polymorphisms
(SNPs) in the RAGE, S100A8 and HMGB1 genes using sequencespecific primer polymerase chain reactions. Intensive care unit length of stay, duration of level 3 care, post-operative neutrophil and white blood cell count (WCC), C-reactive protein (CRP) and $\mathrm{PaO}_{2}$ : $\mathrm{FiO}_{2}$ ratio were used as clinical outcome measures.

Results All SNPs conformed to Hardy-Weinberg equilibrium. Patients carrying the $\mathrm{C}$ alleles of rs3795391 and rs3806232 SNPs, in linkage disequilibrium in the $5100 \mathrm{~A} 8$ gene, had a higher neutrophil and WCC ( $p=0.019, p=0.039$ respectively) and a lower $\mathrm{PaO}_{2}: \mathrm{FiO}_{2}$ $(p=0.01)$ on post-operative day 3. Median post-operative $\mathrm{PiO}_{2}: \mathrm{FiO}_{2}$ of patients carrying the $\mathrm{C}$ alleles versus those not was $123.5 \mathrm{~mm} \mathrm{Hg}$ vs $204.4 \mathrm{~mm} \mathrm{Hg}$. Patients carrying the GG genotype of the rs2070600 (Gly82Ser) SNP in the RAGE gene had a higher neutrophil count on post-operative day $2(\mathrm{p}=0.025)$. Patients carrying the $\mathrm{T}$ allele of the RAGE rs1800624 (-374T/A) SNP had higher CRP levels on post-operative day $1(\mathrm{p}=0.015)$.

Conclusion SNPs in the RAGE and S100A8 genes are associated with the intensity of the systemic inflammatory response and patient oxygenation levels in our cohort of patients following snCPB. Patients carrying the $\mathrm{C}$ alleles of the S100A8 SNPs had significantly impaired oxygenation in the early post-operative period compared to patients carrying the TT genotype, suggesting a genetic influence on the degree of lung injury arising as a result of snCPB. Pre-operative genotyping for polymorphisms associated with adverse outcomes may be used to stratify patients' risk from snCPB, allowing the development of interventions designed to reduce postoperative morbidity and mortality.

\section{S107 COMPARISON OF HIGH-STRETCH VERSUS ATELECTASIS IN THE PATHOPHYSIOLOGY OF VENTILATOR-INDUCED LUNG INJURY USING THE MOUSE ISOLATED PERFUSED LUNG}

doi:10.1136/thx.2010.150946.8

K Wakabayashi, M R Wilson, K P O'Dea, M Takata. Section of Anaesthetics, Pain Medicine and Intensive Care, Imperial College London, London, UK

Introduction Mechanical ventilation promotes pulmonary inflammation and oedema formation, a process known as ventilatorinduced lung injury (VILI). Various aspects of ventilation have been proposed as injurious, including over distension of alveoli and the repetitive collapse and reopening of lung units associated with atelectasis. Here we attempt to elucidate the impact of these distinct entities on the pathophysiology of VILI, using a mouse isolated perfused lung, which enables us to study the effects of stretch versus atelectasis in the absence of extra pulmonary factors. Methods Lungs were obtained from male C57BL6 mice, and allocated to one of three groups, that is, control, atelectasis or highstretch. All the lungs were ventilated with respiratory rate of $80 /$ min, and perfused at $25 \mathrm{ml} / \mathrm{kg} / \mathrm{min}$ in a recirculating manner with non-blood buffer for $3 \mathrm{~h}$. In the control group, low tidal volume $\left(7 \mathrm{ml} / \mathrm{kg}\right.$ ) with positive end-expiratory pressure (PEEP; $5 \mathrm{cmH}_{2} \mathrm{O}$ ) and regular deep inflation (DI; $25 \mathrm{cmH}_{2} \mathrm{O}$, every $15 \mathrm{~min}$ ) was applied. The atelectasis group received the same low tidal volume, but neither PEEP nor DI. In the high-stretch group, lungs were ventilated with high tidal volume $(30-32 \mathrm{ml} / \mathrm{kg})$ and both PEEP $\left(3 \mathrm{cmH}_{2} \mathrm{O}\right)$ and DI. Perfusate and lung lavage samples were taken at the end of experiments for analysis of total protein and chemokines. Results The lungs in the atelectasis and high-stretch groups developed similar, severe pulmonary oedema as represented by increases in protein levels in lavage fluid. High-stretch induced substantial increases in both perfusate and lavage fluid chemokines, compared to controls. In stark contrast, the atelectasis group showed similar low levels of chemokines in perfusate, with only slight increases in lavage fluid chemokines, compared to controls (Abstract S107 Table 1). 
Abstract S107 Table 1

\begin{tabular}{llll}
\hline & Control $(\mathbf{n}=\mathbf{5})$ & High-stretch $(\mathbf{n}=\mathbf{3})$ & Atelectasis $(\mathbf{n}=\mathbf{5})$ \\
\hline $\begin{array}{l}\text { Protein in lavage fluid } \\
\text { (mg/ml) }\end{array}$ & $0.21 \pm 0.04$ & $4.07 \pm 2.21^{*}$ & $4.81 \pm 1.67^{*}$ \\
$\begin{array}{l}\text { Perfusate chemokines } \\
\text { MIP-2 (ng/ml) }\end{array}$ & $1.12 \pm 0.70$ & $4.29 \pm 0.82^{*} \dagger$ & $1.48 \pm 0.67$ \\
KC (ng/ml) & $1.26 \pm 0.74$ & $6.71 \pm 1.79^{*} \dagger$ & $1.70 \pm 1.09$ \\
Lavage fluid chemokines & & & \\
MIP-2 (ng/ml) & $0.13 \pm 0.06$ & $4.39 \pm 1.98^{*} \dagger$ & $0.69 \pm 0.26^{*}$ \\
KC (ng/ml) & $0.12 \pm 0.04$ & $5.15 \pm 1.42^{*} \dagger$ & $0.82 \pm 0.47^{*}$ \\
\hline
\end{tabular}

${ }^{*} \mathrm{p}<0.05$ versus control.

$t p<0.05$ versus atelectasis.

MIP-2, Macrophage-inflammatory protein-2; KC, Kerationocyte-derived chemokine.

Conclusion While both high-stretch and atelectasis can induce barrier dysfunction, only high-stretch induced substantial production of chemokines by the lung and their release into the circulation. These findings suggest that over distension of the lung, rather than collapse/reopening associated with atelectasis, primarily contributes to the exacerbated pulmonary and systemic inflammation during VILI. Our results may provide insights into why addition of PEEP to limit atelectasis has limited clinical outcome benefit in ventilated patients with acute lung injury.

\section{Epidemiology of lung disease S108 A HISTORICAL COHORT STUDY TO DETERMINE THE PREVALENCE OF COMMON CHRONIC RESPIRATORY DISEASES AND MEDICATION USE IN DRUG MISUSERS}

doi:10.1136/thx.2010.150946.9

F Palmer, M Jaffray, M Moffat, C Matheson, J Haughney, A Coutts. University of Aberdeen, Aberdeen, Scotland

Introduction and aim A local substance misuse study and anecdotal evidence from primary care, suggested many methadone patients have respiratory disease and/or prescriptions for respiratory preparations. Anecdotal evidence from clinical colleagues supports this. With little published literature in this area, this preliminary study aimed to explore the prevalence of respiratory diseases and prescriptions for respiratory medication in drug misusers.

Method This exploratory study used a historical cohort design with matched controls. An analysis of Primary Care Clinical Informatics Unit (PCCIU) GP consultation data was conducted. The prevalence of common respiratory diseases (ever appearing in the patient's medical records) and commonly used respiratory prescriptions (in 2008) between drug misusers and matched controls (general population sample) was compared.

Results The PCCIU data contained a cohort of 18570 patients (9285 per group), of which, $64 \%(n=11885)$ were male and $75.7 \%$ $(n=14060)$ were aged $31-59$. Results revealed an increased prevalence of chronic respiratory disease in drug misusers versus controls. Drug misusers were more likely to be prescribed chronic respiratory diseases medications than controls. These results were still significant when adjusted for smoking status, where those who had never smoked were compared to those who had ever smoked (current and ex smokers) (See Abstract S108 Table 1). Median quantity of SABA and ICS prescriptions during 2008 were also statistically significantly higher in drug misusers*. The median quantity of SABA prescribed for drug misusers were 4 (IOR 2-8) vs 3 (IOR 1-7) in controls**. The median quantity of ICS prescribed for drug misusers were 4 (IOR 2-8) vs 2 (IOR 1-5) in controls**. *Median Prescription for patients on $\geq 1$ prescription. ${ }^{* *} \mathrm{p}<0.001$ Mann-Whitney U.
Abstract S108 Table 1 Comparisons using PCCIU SPICE data

\begin{tabular}{|c|c|c|c|c|}
\hline & Drug misusers & Controls & $\begin{array}{l}\text { Crude OR } \\
(95 \% \mathrm{CI})\end{array}$ & $\begin{array}{l}\text { Adjusted OR } \\
\text { (95\% CI) }\end{array}$ \\
\hline Asthma diagnosis & $1590(17.1 \%) \dagger$ & $1009(10.9 \%) \dagger$ & $\begin{array}{l}1.695(1.557 \\
\text { to } 1.845) \neq\end{array}$ & $\begin{array}{l}1.633(1.485 \\
\text { to } 1.796) \ddagger\end{array}$ \\
\hline $\begin{array}{l}\text { COPD (chronic } \\
\text { obstructive } \\
\text { pulmonary disease) } \\
\text { diagnosis }\end{array}$ & $219(2.4 \%) \dagger$ & $74(0.8 \%) \dagger$ & $\begin{array}{l}3.007(2.307 \\
\text { to } 3.920) \neq\end{array}$ & $\begin{array}{l}1.752(1.336 \\
\text { to } 2.297) \neq\end{array}$ \\
\hline $\begin{array}{l}\text { SABA (short acting } \\
\beta \text { agonist) } \\
\text { prescribed* }^{*}\end{array}$ & $1520(16.4 \%) \dagger$ & $736(7.9 \%) \dagger$ & $\begin{array}{l}2.274(2.071 \\
\text { to } 2.496) \ddagger\end{array}$ & $\begin{array}{l}1.998(1.803 \\
\text { to } 2.214) \ddagger\end{array}$ \\
\hline $\begin{array}{l}\text { LABA (long acting } \\
\beta \text { agonist) } \\
\text { prescribed* }\end{array}$ & $92(1 \%) \dagger$ & $39(0.4 \%) \dagger$ & $\begin{array}{l}2.373(1.630 \\
\text { to } 3.454) \ddagger\end{array}$ & $\begin{array}{l}1.883(1.255 \\
\text { to } 2.825) \neq\end{array}$ \\
\hline $\begin{array}{l}\text { ICS (inhaled } \\
\text { corticosteroid) } \\
\text { prescribed }^{*}\end{array}$ & $987(10.6 \%) \dagger$ & $702(7.6 \%) \dagger$ & $\begin{array}{l}1.454(1.314 \\
\text { to } 1.609) \ddagger\end{array}$ & $\begin{array}{l}1.500(1.339 \\
\text { to } 1.681) \neq\end{array}$ \\
\hline
\end{tabular}

Conclusion These data suggest, drug misusers have a significantly higher prevalence of respiratory diseases and are prescribed significantly more respiratory medications than matched controls. Adjusting for smoking status, still revealed drug misusers have significantly increased odds of have a respiratory disease or being prescribed respiratory medication, indicating there may be more complex factors involved related to drug use needing further exploration. As a first stage exploratory study, we have set the scene for future work to begin to determine the potential reasons for this association.

\section{S109 CURRENT COPD CARE IN THE UK; RESULTS FROM 180000 PATIENTS IN THE POINTS DATABASE}

doi:10.1136/thx.2010.150946.10

${ }^{1}$ A De Soyza, ${ }^{2} \mathrm{~J}$ Roberts. ${ }^{1}$ Newcastle University /Freeman Hospital, Newcastle upon Tyne, UK; ${ }^{2}$ Salford Royal Hospital NHS Foundation Trust and NHS Salford, Salford, UK

Background COPD is a major healthcare burden in the UK with one million diagnosed patients. Despite a number of evidence-based guidelines, managing COPD is not straightforward. Differing standards of care exist; those qualifying for Quality \& Outcomes Framework QOF versus Non-incentivised NICE guidelines.

Aims To define a large UK wide COPD cohort and describe their current care as recorded in primary care databases.

Methods We interrogated the POINTS ${ }^{1}$ database of all participating practises in the UK. Data were collected between 2007and 2009.

Results 1406 GP Practices participated with total list size $\sim 7.9$ million of these $\sim 180000$ COPD patients were listed. 1009 practices returned list sizes giving approximately $1.8 \%$ prevalence of COPD. Approx 45000 (25\%) were current smokers of these 31000 (69\% of smokers) had received recent smoking cessation education $30 \%$ were of working age ( $<65$ years). $96000(50 \%)$ had a FEV 1 recorded within 12 months, 147000 had flu and/or pneumococcal vaccination status recorded (80\%). Only 15\% (27500) had exacerbation frequency recorded. Progressive increases in MRC dyspnoea score (MRCD) recording occurred each year from 2007 at $29 \%$ to $44 \%$ in 2009. The most common prescription was short acting $\beta$ agonist SABA in $66 \%$, Inhaled corticosteroid/Long acting $\beta$ agonist (ICS/LABA) combination inhaler in $47 \%$, LAMA (long acting muscarinic antagonist) in 30\%. We noted $27514(15 \%)$ were prescribed an ICS inhaler which is out of licence and against NICE guidelines. $6 \%$ were prescribed a mucolytic.

Conclusions This cohort is one of the largest reported. Certain limitations may apply: possible non-random participation of practises, incorrect COPD diagnosis and incomplete datasets. Despite exacerbation rate reduction being a key management goal, 